\title{
REGIONAL FLOOD FREQUENCY ANALYSIS USING LINEAR MOMENTS AND PARTIAL LINEAR MOMENTS: A CASE STUDY
}

\author{
AhMAD, I. ${ }^{12^{*}}-$ WAQAS, M. $^{2}$ - AlmANJAHIE, IBRAHIM M. ${ }^{1}-$ SAghiR, A. ${ }^{3}$ - HAQ, E. U. ${ }^{2}$ \\ ${ }^{I}$ Department of Mathematics, College of Science, King Khalid University, 61413 Abha, \\ Kingdom of Saudi Arabia \\ ${ }^{2}$ Department of Mathematics and Statistics, Faculty of Basic and Applied Sciences, \\ International Islamic University, 44000 Islamabad, Pakistan \\ ${ }^{3}$ Department of Mathematics, MirPur University of Science and Technology \\ 10250 Mirpur, Azad Jammu Kashmir, Pakistan \\ *Corresponding author \\ e-mail: ishfaq.ahmad@iiu.edu.pk; phone: +96-659-681-7557
}

(Received $7^{\text {th }}$ Jan 2019; accepted $22^{\text {nd }}$ Feb 2019)

\begin{abstract}
One of the major concerns in Flood Frequency Analysis (FFA) is to predict floods of high magnitude for larger return periods. Magnitudes of smaller floods behave as nuisance in the estimation of larger floods. In this study, to avoid the unnecessary effect due to smaller observations, we implemented the technique of left censoring. The primary objective of this study is to see the efficacy of censoring, by comparing Regional Flood Frequency Analysis (RFFA) using Partial Linear Moments (PLM) for censored samples with RFFA using Linear Moments (LM) for uncensored samples of annual peak flows observed at ten stations of Indus Basin in Pakistan. After fulfillment of fundamental assumptions of randomness, independence, homogeneity, and stationarity, a Grubbs-Beck (GB) test for outlier detection is applied to the samples from all stations. For further analysis, Discordancy measure shows that none of the site is discordant and all ten stations would be retained for further investigation. On the basis of geographical closeness, stream hydrology and morphology of Indus basin, a single homogenous region is proposed and testified by the heterogeneity standards. The best fit distribution is selected by implying the Z-statistic (goodness of fit test base on LM) and L-Moments Ratio Diagram (LMRD). Generalized Pareto Distribution (GPA) distribution under PLM while Generalized Normal Distribution (GNO) under LM is selected as the reasonable choice for design flood estimation. Monte Carlo simulation experiment is performed to check the efficacy of PLM over LM through Root Means Square Error (RMSE) and bias. These accuracy measures indicated the outperformance of censored samples under PLM to uncensored samples under LM.
\end{abstract}

Keywords: discordancy, heterogeneity, design flood estimation, censored samples, uncensored samples

Abbreviations: Regional Flood Frequency Analysis (RFFA); Flood Frequency Analysis (FFA); Partial Linear Moments (PLM); Linear Moments (LM); Grubbs-Beck (GB); Generalized Pareto Distribution (GPA); Generalized Normal Distribution (GNO); Generalize Logistic (GLO); Generalize Extreme Value (GEV); Generalize Pearson 3 Type (PE3); Root Means Square Error (RMSE); Pakistan Meteorological Department (PMD); Partial Probability Weighted Moments (PPWM).; Probability Weighted Moments (PWM); Annual Peak Flows (APF); Index Flood Procedure (IFP); Censored (C); Uncensored (UC); LMoments Ratio Diagram (LMRD); Partial L-Moments Ratio Diagram (PLMRD)

\section{Introduction}

Changing climate around the globe is the major challenge of today's world. Global warming leads to many changes in climatic conditions, which ultimately induce to changes in the intensity, spatial extent, frequency, duration and timing of extreme weather and climate events such as bolstering heat waves, lengthening droughts and causing more precipitation and flooding. In Pakistan, climate change has also resulted in extreme 
weather conditions such as torrential rainfalls, irregular floods, droughts, glacier melting, sea-level rising, etc. (Rasul et al., 2012). Currently, Pakistan is among the top ten countries that are vulnerable to the adverse effects of climate change. Pakistan Meteorological Department (PMD) reported that due to an abrupt change in climate during the past three decades a 100 kilometres spatial shift towards the west as well as the seasonal shift in the overall monsoon distribution pattern is observed in Pakistan. For example, the summer monsoon has moved towards the end of the season, and the winter rains have also driven towards late February and March (Ali, 2013).

In Pakistan, monsoon season is one of the major causes of heavy floods. Monsoon rains and floods usually create havoc in different parts of the country leaving thousands of families affected, a large number of houses destroyed, thousands of acres of ready to harvest crops and fruits orchards damaged, link roads and bridges destroyed. The resulting consequences of floods could be mitigated by improving water resources management. This goal could be achieved by collecting accurate information about the estimation of floods magnitude and frequency of occurrence, which ultimately would be helpful in designing, planning, and management of different hydrological structures such as water reservoirs, spillways, headworks, dams, culverts, bridges and other hydrological related structures. Water resources management could be strengthened by exploring flood frequency analysis and making headworks and stations attuned to water flows (Zin et al., 2009).

To improve above mentioned perspectives, there are two approaches of frequency analysis commonly used in hydrology. First one refers to at-site flood frequency analysis while the second one as regional flood frequency analysis. In at-site frequency analysis, we analyze the results of each site or station individually instead of grouping the information from all sites (Zin et al., 2009; Seckin et al., 2011; Ahmad et al., 2015, 2016a; Afreen and Muhammad, 2012; Rahman et al., 2013; Asikoglu, 2018). At-site frequency analysis is not a promising technique in the presence of small data and non-availability of data at ungauged stations. Due to data scarcity and sampling variability, RFFA is considered as more reliable technique providing information by using multiple sites and grouping them on the basis of similarity of their hydrological and geographical characteristics. RFFA based on Index Flood Procedure (IFP) is more helping and practical technique in providing design flood estimates for different sites especially in the presence of small data or no data at some sites in the region (Yue and Wang, 2014).

This method, with probability weighted moments (PWM) scheme has shown more promising results in the homogeneous regions. PWM was initially introduced by (Greenwood et al., 1979) and further, the L-moments technique was proposed by Hosking (1990). In design flood estimation, our primary goal is the evaluation of larger events on right tail of the frequency distribution. In this situation, practically small flood events are of little relevance and sometimes put unnecessary influence in design flood estimation of larger events. This problem can be tackled with the help of left censoring. We can discard the smaller flood events using some criterion to get rid of the unnecessary effects which they put on the estimation of larger flood events.

Under this motivation, we employed PLM method for censored samples (the samples in which some small values have been discarded) in characterizing the larger events for better water resources management. PLM is an extension of LM and is based on Partial Probability Weighted Moments (PPWM). With the help of PLM, we could mitigate the undesirable influences of small events which they leave on the estimation of higher return period events. RFFA based on method of LM had been successfully applied in many 
countries across the world, For example: in South Africa (Kjeldsen et al., 2002), Malaysia (Mohd Baki et al., 2015), Turkey (Saf, 2009, 2010), Australia (Zaman et al., 2012; Eslamian, 2014), China (Zhang et al., 2015; Du et al., 2014; Yang et al., 2010a, b), Italy (Noto and La Loggia, 2009; Caporlai et al., 2018), Pakistan (Hussain, 2011; Ahmad et al., 2017, 2016b), Tunisia (Abida and Ellouze, 2007), Canada (Glaves and Waylen, 1997); UK (Fowler and Kilsby, 2003), India (Ngongondo et al., 2011; Bora and Borah, 2017), Iran (Khanmohammadi et al., 2018) and Korea (Sung et al., 2018; Kar et al., 2017).

The initial work on PPWM was proposed by Wang (1996) on censored flood samples by fitting Generalized Extreme Value (GEV) distribution. The idea of PPWM is based on the extension of PWM as by Wang (1990, 1996) and Hosking (1990). Partial L-moments could be derived from PPWM on the same lines as L-moments from PWM. Bhattarai (2004), discussed the matter of various censoring levels and revealed that Partial L moments and L-moments show similar properties up to $30 \%$ censoring of the flood samples. Moisello (2007) compared PPWM and PWM and found that in case of unknown parent distribution, PPWM is better than PWM. Kochanek et al. (2008) used PPWM for $\log$ Gumble distribution censoring the largest observation in the sample. In Malaysia, some work has been conducted on PLM; see for example (Zakaria et al., 2011, 2012, 2017; Zakaria and Shabri, 2013). In recent years, Khan et al. (2017) used the method of LM and PLM for quantile estimation of extreme precipitation in Pakistan. In this study, we analyzed and compared the performance of the PLM method for censored with method of LM for uncensored samples implementing RFFA of annual peak flows of ten stations on Indus basin in Pakistan. The primary objectives of the study is to see the efficacy of censoring and to compare RFFA under PLM and LM using data of annual peak flows observed at ten stations of Indus Basin in Pakistan. Secondary objective of the study is to estimate the quantiles of upper tail of the distribution and get knowledge about the larger return periods, which would be helpful in designing, planning, and management of different hydrological structures such as water reservoirs, spillways, headworks, dams, culverts, bridges and other hydrological related structures.

\section{Materials and methods}

\section{Study area}

Irrigation and hydrological structure of Pakistan is world's remarkable irrigation system. Pakistan's hydrological structure is mainly stretched under the umbrella of Indus basin that comprises of three main reservoirs namely Chashma, Mangla, and Tarbela, 19 stations, 12 linking canals, about $56,000 \mathrm{~km}$ of canals, and 110,000 km of watercourses. The climate of the Indus Basin plains varies from semi-arid to arid with temperature ranges from 2 to $49{ }^{\circ} \mathrm{C}$. The Indus River is one of the main transboundary rivers in Asia with nine tributaries (rivers). Among these five tributaries lie on its left bank that are Beas, Chenab, Jhelum, Ravi, and Sutlej rivers. Among these five tributaries, three tributaries as Beas, Ravi, and Sutlej are also transboundary rivers having upper catchments in India. On the other side, right bank tributaries are the Gomal, Kabul, Swat and Kurram rivers. According to the Indus Water Treaty (1960) between Pakistan and India, the water from three rivers (Beas, Sutlej and Ravi) has been allocated to India while of other three rivers (Jhelum, Chenab and Indus) to Pakistan. Based on its morphology and stream hydrology, the Indus River can be divided into three segments: (i) the upstream segment (ii) the midstream segment, (iii) and the downstream segment. The upstream segment ranges from the Singi Khahad spring down to Jinnah Barrage being a 
hilly catchment area. The midstream segment, prolongs from Jinnah to Guddu stations being an upper floodplains area dominated by an intervening pattern of channels and river inflows. The last one, the downstream segment, ranges from Guddu Barrage to the Arabian Sea, is a lower flood plains area and has a flat topography, a meandering channel pattern and deltas (Ali, 2013). These ten stations are located on the three rivers, the Jhelum, Chenab and Ravi (mid segment) and Indus River/Sindh (lower segment). Stations Location, latitude, longitude, elevation, length and drainage area are given in Table 1 and geographical locations are depicted in Figure 1.

\section{Basic assumptions of the data}

First of all, we will check the basic assumptions important for a hydrological analysis such as, homogeneity, randomness/independence and stationarity for the data from all stations.

\section{Assumption of homogeneity}

The term homogeneity refers to the notion that all elements of a sample belonging to a single common population. Because the sample of flood data may arise in the result of ordinary rainfall or extraordinary rainfall with high intensities and volumes resulting from extreme hydrometeorological conditions. In these scenarios, we may face nonhomogeneous sample of flood data. To check the assumption of homogeneity we apply Mann and Whitney test.

\section{Assumption of independence and randomness}

In frequency analysis, the idea of independence postulates that none of the peak flow in the sample will affect the occurrence or non-occurrence of any other value in the same sample. Randomness implies that each element of the sample is independently drawn at random from the population with equal probability. In this study we apply, Wald and Wolfowitz test to check the independence and randomness assumption for the observed data from all stations. The same test has been used in different studies for the same purpose see for example Naghettini (2017) and Hussain (2011).

Table 1. Basic information of different stations in the study

\begin{tabular}{c|c|c|c|c|c|c}
\hline $\begin{array}{c}\text { Rivers } \\
\text { names }\end{array}$ & Site name & $\begin{array}{c}\text { Latitude } \\
\text { (degrees } \\
\text { north) }\end{array}$ & $\begin{array}{c}\text { Longitude } \\
\text { (degrees } \\
\text { east) }\end{array}$ & Altitude & $\begin{array}{c}\text { Length of the } \\
\text { basin (feet) }\end{array}$ & $\begin{array}{c}\text { Drainage area } \\
\left(\mathbf{k m}^{\mathbf{2}}\right)\end{array}$ \\
\hline \multirow{2}{*}{ Jhelum } & Mangla & 33.15 & 73.65 & 774 & 10,300 & 20712 \\
& Rasul & 32.68 & 73.5 & 699 & 3209 & 24069 \\
\hline \multirow{2}{*}{ Chenab } & Marala & 32.68 & 74.43 & 702 & 4472 & 31148 \\
& Khanki & 32.4 & 73.2 & 666 & 4000 & 29732 \\
& Qadirabad & 32.33 & 73.73 & 639 & 3373 & 2585 \\
\hline \multirow{2}{*}{ Ravi } & Balloki & 31.22 & 73.86 & 600 & 1644 & 63712 \\
& Sidhnai & 30.58 & 72.07 & 426 & 712 & 4709 \\
\hline \multirow{2}{*}{ Sindh } & Kotri & 25.22 & 68.22 & 55 & 3000 & 25485 \\
& Guddu & 28.3 & 69.5 & 222 & 3840 & 25485 \\
& Sukkur & 27.72 & 68.79 & 201 & 4490 & 42475 \\
\hline
\end{tabular}




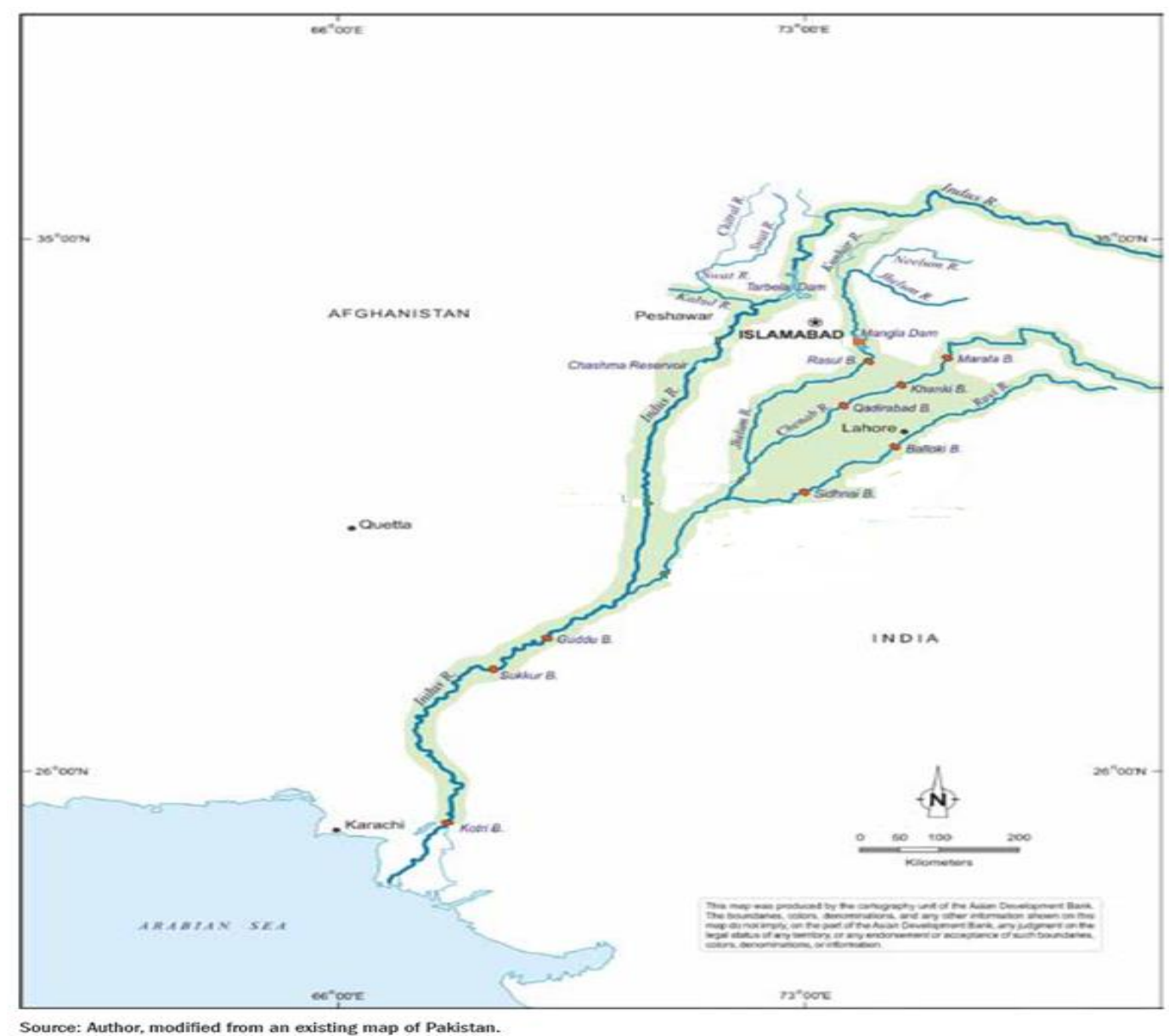

Figure 1. Geographical location of different stations in the study

\section{Assumption of stationarity}

In general, stationarity of hydrological variable implies the invariance over time of some statistical properties of a hydrological variable such as its probability distribution and related parameters (Naghettini, 2017). Usually, we face monotonic trend in hydrology. For measurement of this kind of trend, we can use Spearman's rank correlation coefficient test. It is a nonparametric procedure to test the statistical dependence between two variables. Statistical dependence is not restricted to be linear as in case of simple correlation coefficient test. The basic notion behind this test is that the trend hidden in a flood data evolving over time can be measured with the help degree of association or correlation between ranking orders " $m_{t}$ " of original series and corresponding time indices $T_{t}$.

\section{Outliers detection and Grubbs-Beck (GB) test}

In frequency analysis of extreme events like droughts, floods and others, it is very common to have some observation below some threshold value. These values are of little interest, especially, when your interest is in modeling the right tail of the distribution, i.e. estimating the higher return periods of extreme events. In a given sample, a value is treated as an outlier if it shows a significant departure from the overall tendency of other sample values due to any reason. The reason might be measurement error or processing or some other. In any case, these outliers may severely influence parameters and quantiles 
estimation and in general fitting process of the probability distribution. Once an outlier is detected in the sample, the decision of its removal or not removal needs further investigation. If its removal is conclusive, then it must be censored or removed from the sample. These observations are nuisance in the frequency analysis and problematic for the validity of the end results. In such situation, it is good practice to censor these observations in order to understand the process in a better way. In frequency analysis of annual peak flows or rainfall, the removal of an outlier from the lower side (left censoring) is justified because our main concern is an estimation of upper tail quantile or high return period's events. However, if some outlier is detected from the upper side, it should not be expunged from the sample because it might be due to some natural causes or extraordinary hydrometeorological conditions and helpful in estimating larger return periods events (Naghettini, 2017). Among other tests for outlier detection in statistical hydrology, the Grubbs- Beck (GB) test is the most frequently used test. This test defines two bounds, $X_{U}$ upper bound and $X_{L}$ lower bound, as given in Equations 1 and 2. Any value below or above these bounds would be treated as an outlier in the ranked sample values, where

$$
\begin{aligned}
& X_{U}=\exp \left(\overline{x^{8}}+K_{n, \alpha} S_{X}^{*}\right) \\
& X_{L}=\exp \left(\overline{x^{*}}-K_{n, \alpha} S_{X}^{*}\right),
\end{aligned}
$$

where, $\overline{x^{*}}$ and $s_{x}^{*}$ are the mean and standard deviation of logarithms of original data of annual peak flows. In Equations 1 and 2, $K_{n, \alpha}$ shows the critical values of the GB test statistics. The critical values for GB test statistic at 5\% level of significance with sample size (n), ranges from 10 to 120, could be found as in Equation 3.

$$
K_{n, \alpha=0.05}=-5.2269+8.768 n^{0.025}-3.8063 n^{0.5}+0.8011 n^{0.75}-0.0656 n,
$$

\section{Methods of estimation}

\section{Method of linear moments (L-moments)}

PWM primarily was defined by Greenwood et al. (1979), and later LM (linear moments) by Hosking (1990). The PWM of order $r$ was defined by Greenwood et al. (1979) as Equation 4:

$$
\beta_{y}=\int_{0}^{1} x(F) F^{y} d F_{s}
$$

where $x(F)$ is quantile function and $F=F(\mathrm{x})$ is the cumulative distribution function. The first four L moments as a linear combination of PWM's are described below:

$$
\begin{array}{cc}
\lambda_{1}=\beta_{0} & \text { (First L-moment as measure of central tendency) } \\
\lambda_{2}=2 \beta_{1}-\beta_{0} & \text { (Second L-moment as measure of dispersion) } \\
\lambda_{\mathrm{a}}=6 \beta_{2}-6 \beta_{1}+\beta_{0} & \text { (Third L-moment as measure of skewness) } \\
\lambda_{4}=20 \beta_{\mathrm{a}}-30 \beta_{2}+12 \beta_{1}-\beta_{0} & \text { (Fourth L-moment as measure of kurtosis) }
\end{array}
$$




$$
\begin{array}{ll}
\tau_{2}=\frac{\lambda_{2}}{\lambda_{1}} & \text { (Measure of coefficient of variation based on L-moments) } \\
\tau_{a}=\frac{\lambda_{3}}{\lambda_{2}} & \text { (Measure of coefficient of skewness based on L-moments) } \\
\tau_{4}=\frac{\lambda_{4}}{\lambda_{2}} & \text { (Measure of coefficient of kurtosis based on L-moments) }
\end{array}
$$

In practice, for $r=0,1,2,3 \ldots . n$, LM could be estimated from sample PWMs by Equation 5:

$$
b_{r}=\frac{1}{n} \sum_{i=r+1}^{n} \frac{(i-1)(i-2)]_{n}(i-r)}{(n-1)(n-2)_{m}-(n-r)} x_{i n}
$$

The relationship of both sample LM and PWM is determined by Equation 6:

$$
l_{r+1}=\sum_{k=0}^{*} p_{\gamma}^{*} b_{k} r=0,1,2, \ldots \ldots \ldots(n-1) \text {. }
$$

For $r=0,1,2,3 \ldots n$, we obtain:

$$
\begin{gathered}
l_{1}=b_{0} \\
l_{2}=2 b_{1}-b_{0} \\
l_{2}=6 b_{2}-6 b_{1}+b_{0} \\
l_{4}=20 b_{a}-30 b_{2}+12 b_{1}-b_{0}
\end{gathered}
$$

Sample version of coefficient of variation, skewness and kurtosis based on LM can be defined by replacing the population values with sample estimates of LM; denoted by $t_{s} t_{2}$, and $t_{4}$ respectively.

\section{Method of partial linear moments (PLM)}

Wang (1996) extended the idea of probability weighted moments (PWM) and defined PPWM for censored samples as Equation 7:

$$
\beta_{y}^{s}=\frac{1}{1-F_{0}^{r+1}} \int_{F_{0}}^{1} x(F) F^{r} d F_{x}
$$

where $F_{0}$ is varying point and could be $10 \%, 20 \%$ or $30 \%$; it is also called censoring threshold. Note that, if $F_{0}=0$, the partial L moments becomes simple L moments. The unbiased estimates of $\beta_{r}^{s}$ can be defined as Equation 8:

$$
b_{r}^{p}=\frac{1}{\left(1-F_{0}^{r+1}\right) n} \sum_{i=1}^{n} \frac{(i-1)(i-2)_{m \ldots m}(i-r+1)(i-r)}{(n-1)(n-2)_{m-n}(n-r+1)(n-r)} x_{(i)}^{*}
$$

where:

and

$$
x_{(\mathbb{1})}^{*}=0 \text { for } x_{(\mathbb{1})} \leq x_{0}
$$

$$
x_{(\mathbb{0})}^{*}=x_{(\mathbb{1})} \text { for } x_{(\mathbb{0})}>x_{0}
$$


The censoring level tells about the number of sample values to be censored as $F_{0}=\frac{m_{0}}{n}$; where $n_{0}$ and $n$ are the number of censored values determined through GB test) and the length of the complete sample respectively. The first four PLM are parallel to first four LMs by replacing PWM by PPWM. In this study, they are denoted by $\xi_{1}, \xi_{2}, \xi_{3}, \xi_{4}$.

The relationships for " $S_{2}{ }^{1 "}$ (Coefficient of variation based on partial $\mathrm{L}$ moments), " $\mathrm{Sa}_{\mathrm{a}}{ }^{\mathrm{I}}$ (Coefficient of skewness based on partial L moments) and "S4" (Coefficient of kurtosis based on partial L moments) are defined as Equation 9:

$$
\varsigma_{2}=\frac{k_{2}}{k_{1}}, \varsigma_{a}=\frac{k_{3}}{k_{2}} \text { and } \varsigma_{4}=\frac{k_{4}}{k_{2}}
$$

Sample version of coefficient of variation, skewness and kurtosis based on PLM can be defined by replacing the population values of PPWMs by their sample counterparts and denoted by $t^{\prime}, t_{\mathrm{a}}$, and $t_{4}$.

\section{Regional flood frequency analysis (RFFA) using LM and PLM}

Hosking and Wallis (1997) provided a comprehensive RFFA procedure using linear moments theory. It consists of mainly four steps.

\section{Data screening}

For RFFA, the first step is the initial screening of data. The sites with a trend and showing some gross error are excluded from the rest of sites. Hosking and Wallis (2005) suggested a discordancy measure $D_{i}$ using LM to distinguish those sites which are discordant from other sites. For $i=1_{, \ldots,} n_{x} D_{i}$ is given by

$$
D_{i}=\frac{1}{a}\left(u_{i}-\bar{u}\right)^{T} S^{-1}\left(u_{i}-\bar{u}\right)
$$

where $S=\frac{1}{N-1} \sum_{i=1}^{N}\left(u_{i}-\bar{u}\right)\left(u_{i}-\bar{u}\right)^{T}$ is a matrix of sum of squares and cross products. Note that $u_{i}=\left[t^{(\bar{D})}, t_{a}^{(\hat{D})}, t_{4}^{(\mathrm{i})}\right]$ is a vector consisting sample LM ratios, $\bar{u}=N^{-1} \sum_{i=1}^{N} u_{i}$, and $\mathrm{N}$ is the total number of sites

Hosking and Wallis (2005) provided threshold values for $D_{i}$. A site is treated as discordant site if calculated value of $D_{i}$ exceeds the corresponding critical value. Critical values for a different number of sites are given in Table 2. We used the same criterion for detection of discordant sites for censored sample under PLM followed by Zakaria and Shabri (2013).

Table 2. Critical values of discordancy measure for different number of sites

\begin{tabular}{c|c|c|c|c|c|c}
\hline Number of sites in the region & 5 & 6 & 7 & 8 & 9 & 10 \\
\hline Critical values & 1.333 & 1.648 & 1.917 & 2.140 & 2.329 & 2.491 \\
\hline
\end{tabular}

\section{Formation of homogeneous regions}

A homogenous region can be formed using geographical convenience strategy, subjective approach, objective approach and cluster analysis for partitioning, e.g. Kmeans clusters etc. However, the formed region should be confirmed later by the heterogeneity tests. The latter test has been explained by Zakaria and Shabri (2013). In 
our study, we fit four parameter kappa distributions to $1, t, t_{3}^{R}, t_{4}^{R}$ and estimate the parameters of this distribution analytically. After 500 realizations of artificial regions considering ten sites, each site with the same number of values as real data, we calculate mean and standard deviation denoted by $\mu_{V}$ and $\sigma_{V}$ respectively and calculate the heterogeneity statistic given by

$$
\boldsymbol{H}=\frac{\left(\mathbb{V}-\mu_{V}\right)}{\sigma_{V}} .
$$

According to the heterogeneity criterion mentioned in Equation 11, if $H<1$ the region is acceptably homogeneous. If $H$ is in between 1 and 2, it can be possibly heterogeneous. However, when $H \geq 2$, the region is definitely heterogeneous.

\section{Selection of regional frequency distribution}

Selection of the best distribution is possible through different statistical tests and graphical inspections. In this study, we use Z-statistic based on LM and LMRD as suggested by (Zakaria and Shabri, 2013). Regional frequency studies showed that more than one distribution could be marked as best fit. However, the most suitable distribution will be that which also provide robust results. Hosking (1990) marked LMRD as the powerful tool to identify the distribution by the depicting ratio of sample regional skewness and kurtosis. In Z-statistic we assess the quality of fit by evaluating the difference between the L-kurtosis of fitted distribution $\tau_{4}^{\text {Dist }}$ and the regional average L-kurtosis $\tau_{4}^{\mathrm{R}}$. To know the significance of this difference, we compare the difference with the sampling variability of $\mathrm{t}_{4}^{\mathrm{R}}$. The statistics is calculated by using

$$
Z^{\text {Dist }}=\frac{\left(\cos _{4}^{\text {Dist }}-t_{4}^{R}\right)}{\sigma_{4}}
$$

where $\sigma_{4}$, is the standard deviation of $\mathrm{t}_{4}^{\mathrm{R}}$ obtained by repeated simulations of the homogeneous region fitted by Kappa distribution and using same record length of the sites as the observed data. More than one distribution can be selected using the criterion given in Equation 12. Best fit is claimed on the basis of the lowest value of $z^{\text {Dist }}$. In literature, $\left|Z^{\text {Dist }}\right| \leq 1.64$ is the criterion at $90 \%$ confidence level. In case of more than one candidature fulfill this criterion, best fit will be declared that one with $Z^{\text {Dist }}$ near to zero or equal to zero.

\section{Estimation of selected frequency distribution}

In this step, we will estimate the parameters of best fit frequency distribution and regional quantiles (regional growth curve) corresponding to different probabilities of non-exceedance useful in water resources management. Index Flood Procedure (IFP) is a prevailing method to estimate at site quantiles (quantile of every site in the homogeneous region). For a given station, the quantile estimates could be obtained by multiplying the sample estimate of index flood estimate/scaling factor $\mu_{i}$ (which may be an estimate of central tendency of the specific site) with regional quantile function $q(0)$. The latter being a dimensionless quantity is common to all sites in the homogeneous region. The relationship can be defined by Equation 13:

$$
\hat{Q}_{\mathrm{i}}(F)=l_{1}^{(\mathrm{l})} \hat{q}(F), i=1,2,3, \ldots, N,
$$


where $\hat{Q}_{\mathrm{i}}(F)$ refers to at-site quantile function and $l_{1}^{(\mathrm{i})}$ is the estimate of $\mu_{i}$. Results obtained from the statistical analysis may contain some inherent errors and hence are uncertain. To make these results more practical and useful, we must assess the uncertainty of these estimates. One of the reasonable choices to assess this uncertainty is Monte Carlo simulation. A simulation algorithm used in this study is known as Regional L-moments algorithm proposed by Hosking and Wallis (2005). For an $i^{\text {th }}$ site at $m^{\text {th }}$ replication, $\hat{Q}_{i}^{\ln \|}(F)$ is quantile estimate for that site while $Q_{i}(F)$ is the simulated value and $F$ be the probability of non-exceedance. The relative error can be estimated by $\frac{\left[\phi_{i}^{[m]}\left[(F)-Q_{i}(F)\right]\right.}{Q_{i}(F)}$. Further, this quantity could be averaged on the total number of $M$ repetitions to derive relative BIAS and relative RMSE respectively given by

$$
B_{i}(F)=\frac{1}{M} \sum_{m=1}^{M} \frac{\left[Q_{i}^{\mid m \perp}(F)-Q_{i}(F)\right]}{Q_{i}(F)},
$$

and

$$
R_{i}(F)=\left[\frac{1}{M} \sum_{m=1}^{M}\left\{\frac{\left\{Q_{i}^{|m|}\left[(F)-Q_{i}(F)\right\}\right.}{Q_{i}(F)}\right\}^{2}\right]^{\frac{1}{2}}
$$

A summary statistic for accuracy assessment of all sites in the homogeneous region is calculated by regional average relative BIAS and RMSE respectively given by Equation 16:

$$
B^{R}(F)=\frac{1}{N} \sum_{i=1}^{W} B_{i}(F)
$$

and Equation 17:

$$
R^{R}(F)=\frac{1}{N} \sum_{i=1}^{W} R_{i}(F)
$$

It is worth noting that the above assessment measures as given in Equations 14 and 15 deal with the accuracy of quantile estimates of different sites in the region. When our concern is to get the accurate assessment of regional quantile estimates/ growth curve, the quantities $\hat{Q}_{i}^{\lfloor m !}(F)$ and $Q_{i}(F)$ could be replaced with $\widehat{q}(F)$ and $q(F)$, respectively.

\section{Results and discussion}

\section{Data characteristics}

Taking into account the basin's geophysical and hydroclimatic characteristics, the central segment and downstream segments seem more important to assess the severity of floods. We have used Annual peak flows/Annual maximum flows data measured in cusecs (the single maximum value recorded in 24 hours for everyday of the year). This value is the maximum value among 365 values of a year. For every year we have only one value in the sample. In this study, ten stations are selected for RFFA, namely, Mangla (with record length of 87 years), Rasul (with record length of 93 years), Marala (with record length of 90 years), Khanki (with record length of 90 years), Qadirabad (with record length of 45 years), Balloki (with record length of 93 years), Sidhnai (with record length of 90 years), Kotri (with record length of 48 years), Guddu (with record 
length of 30 years) and Sukhur (with record length of 30 years). The required data has been retrieved from Federal Flood Commission of Pakistan for research purpose. The smallest record length of 30 values for 30 years belongs to Guddu and Sukhur stations while the largest record length of 93 values for 93 years belongs to Balloki and Rasul stations. Some basic characteristics of the original sample without censoring are presented in Table 3.

Table 3. Samples statistics with discordancy measure for uncensored (original) samples

\begin{tabular}{c|c|c|c|c|c|c}
\hline Site name & $\begin{array}{c}\boldsymbol{n} \\
\text { record length } \\
\text { of original } \\
\text { sample (years) }\end{array}$ & $\begin{array}{c}\text { Mean of } \\
\text { original sample } \\
\text { (Cusecs) }\end{array}$ & $\begin{array}{c}\boldsymbol{t} \\
\text { (coefficient of } \\
\text { variation) }\end{array}$ & $\begin{array}{c}\boldsymbol{t}_{\mathbf{3}} \\
\text { (coefficient } \\
\text { of skewness) }\end{array}$ & $\begin{array}{c}\boldsymbol{t}_{\boldsymbol{4}} \\
\text { (coefficient } \\
\text { of kurtosis) }\end{array}$ & $\begin{array}{c}\boldsymbol{D}_{\boldsymbol{i}} \\
\text { (discordancy } \\
\text { measure) }\end{array}$ \\
\hline Mangla & 87 & 194352 & 0.4226 & 0.4544 & 0.3467 & 0.77 \\
Rasul & 93 & 202372 & 0.4551 & 0.4412 & 0.2920 & 1.75 \\
Marala & 90 & 317614 & 0.3576 & 0.3659 & 0.1581 & 0.79 \\
Khanki & 90 & 360726 & 0.3520 & 0.3651 & 0.1775 & 0.47 \\
Qadirabad & 45 & 373400 & 0.3764 & 0.2526 & 0.0890 & 1.58 \\
Balloki & 93 & 90667 & 0.3421 & 0.3810 & 0.2242 & 1.12 \\
Sidhnai & 90 & 66534 & 0.4039 & 0.3871 & 0.2133 & 0.42 \\
Kotri & 48 & 382169 & 0.4048 & 0.4094 & 0.3255 & 1.56 \\
Guddu & 30 & 542060 & 0.3272 & 0.2522 & 0.0284 & 0.87 \\
Sukkur & 30 & 491594 & 0.3389 & 0.2596 & 0.0743 & 0.67 \\
\hline
\end{tabular}

Table 3 shows that the value of mean peak flows for Guddu station is maximum as compared to other stations. Coefficient of variation tells us about the relative variation in a data sets. Using the information provided in Table 3, it is obvious that there is more variation in the sample values of Rasul station. The station Guddu carries less variation in all of the ten stations. The most skewed and sharp peak sample belongs to Mangla station. On the other side, sample belongs to station Gudu is less skewed and carries small peak among all stations.

Results of the fundamental assumptions show that annual peak series from all sites fulfill the criteria of randomness, independence, homogeneity, and stationarity. All the probability values (P-Values) are less than 5\% (level of significance), which implies that the hypotheses of randomness, independence and homogeneity are not rejected, and data are suitable for frequency analysis. Further, using Grubbs-Beck test, we determined the number of outliers need to discard from the lower side as well as from upper side. These numbers of observations are discarded from the original sample in order to avoid their unnecessary influence on design flood estimates for higher return periods using PLM. Table 4 shows that none of the observation is declared as outlier from upper side. Different number of observation are discarded from lower side for different stations from the original sample in order to avoid their unnecessary influence on design flood estimates for higher return periods using PLM. The Grubbs-Beck test shows that the maximum number of observation discarded from Rasul station are nine (10\%) while no observation is discarded from Sukhur sample. Numbers of observations smaller than lower limit given by Grubbs-Beck test are treated as censored observations. Although in our study, the numbers of censored values are not too large, but their presence may pertain an unnecessary effect on design flood estimation. To retain larger observations 
in the sample is also justified because it might be due to natural causes or extraordinary hydrometeorological conditions and are also helpful in estimating high return periods (Naghettini, 2017). Results are given in Table 4.

Table 4. Results of fundamental assumptions and outlier detection using origional sample

\begin{tabular}{c|c|c|c|c|c|c|c|c|c}
\hline \multirow{2}{*}{ Site name } & $\begin{array}{c}\text { Wald-Wolfowitz } \\
\text { test }\end{array}$ & \multicolumn{2}{c|}{$\begin{array}{c}\text { Mann-Whitney } \\
\text { test }\end{array}$} & \multicolumn{2}{c|}{$\begin{array}{c}\text { Spearman rank } \\
\text { correlation test }\end{array}$} & \multicolumn{2}{|c}{ Grubbs-Beck test } \\
\cline { 2 - 10 } & Statistic & P-value & Statistic & P-value & Statistic & P-value & $\begin{array}{c}\text { n } \\
\text { (original } \\
\text { sample) }\end{array}$ & $\begin{array}{c}\text { Lower } \\
\text { outliers }\end{array}$ & $\begin{array}{c}\text { Upper } \\
\text { outliers }\end{array}$ \\
\hline Mangla & 1.081 & 01398 & -0.8918 & 0.1863 & -0.6697 & 0.2515 & 87 & 5 & 0 \\
Rasul & 0.7942 & 0.2135 & -0.5185 & 0.3021 & 1.5539 & 0.0601 & 93 & 9 & 0 \\
Marala & 0.7942 & 0.2135 & -0.5185 & 0.3021 & 1.5539 & 0.0601 & 90 & 3 & 0 \\
Khanki & 0.8008 & 0.2116 & -0.8918 & 0.1863 & 0.5451 & 0.2928 & 90 & 6 & 0 \\
Qadirabad & 07286 & 02331 & -0.8503 & 0.1976 & -0.1569 & 0.4376 & 45 & 2 & 0 \\
Balloki & 0.6079 & 0.2716 & -0.8503 & 0.1976 & -1.0171 & 0.1545 & 93 & 8 & 0 \\
Sidhnai & 0.7925 & 0.2140 & -2.1776 & 0.0147 & 2.0187 & 0.0618 & 90 & 7 & 0 \\
Kotri & 1.4308 & 0.0762 & -1.2236 & 0.1106 & -0.3031 & 0.3909 & 48 & 5 & 0 \\
Guddu & -1.4316 & 0.0761 & -0.3111 & 0.3779 & 0.5571 & 0.2887 & 30 & 1 & 0 \\
Sukkur & -0.4560 & 0.3242 & -0.6014 & 0.2738 & 0.1881 & 0.4254 & 30 & 0 & 0 \\
\hline
\end{tabular}

\section{Regional flood frequency analysis}

To know about the discordant site from the group of ten sites, we calculated discordancy measure given in Equation 10. Record length, mean, the coefficient of skewness, the coefficient of kurtosis along with discordancy measure for each station are presented for uncensored and censored samples. Results are presented in Tables 3 and 5 respectively.

The maximum value of $D_{i}$ is 1.75 for Rasul station, while for all other nine sites, $D_{i}$ value is comparatively less. According to the criterion of Table 1 , if the $D_{i}$ value for a site is greater than 2.491 , then that site will be declared as discordant. In present study, none of the sites is exceeding 2.491, none of the site is treated as discordant. Thus, all sites are considered suitable for further procedure. Table 5 describes the results of discordancy measure and other basic statistics using PLM theory for censored data. $C$ denotes discarded values from lower side while $n^{*}$ is sample size after censoring.

A reduction in discordancy measure using the censored sample is obvious as compared original samples. The reason for this change is censoring of data. Our main focus is on the upper tail of the fitted distribution, so these discarded observations might be the nuisance for further analysis. Initially, a single homogenous region is formed and verified by the heterogeneity standards. Seven stations are located in Punjab province while the three in Sindh province. The stations named Sukhur, Guddu and Kotri constitute the lower segment of Indus River. Under morphology and stream hydrology of the Indus basin, it is justified to make one homogenous region from these ten sites. To verify the homogeneity of the region, the heterogeneity is calculated using LM and PLM (see Table 6). 
Table 5. Samples statistics with discordancy measure for censored samples

\begin{tabular}{c|c|c|c|c|c|c|c}
\hline Site name & $\boldsymbol{n}^{*}$ & $\begin{array}{c}\mathbf{C} \\
\text { (No. of censored } \\
\text { values) }\end{array}$ & $\begin{array}{c}\text { Mean } \\
\text { (Cusecs) }\end{array}$ & $\begin{array}{c}\mathbf{t}^{f} \\
\text { (coefficient of } \\
\text { variation) }\end{array}$ & $\begin{array}{c}\mathbf{t}_{\mathbf{3}}^{f} \\
\text { (coefficient } \\
\text { of skewness) }\end{array}$ & $\begin{array}{c}\mathbf{t}_{\mathbf{4}}^{f} \\
\text { (coefficient } \\
\text { of kurtosis) }\end{array}$ & $\begin{array}{c}\mathbf{D}_{\mathbf{i}} \\
\text { (discordancy } \\
\text { measure) }\end{array}$ \\
\hline Mangla & 82 & 5 & 199414 & 0.4138 & 0.4662 & 0.2070 & 0.72 \\
Rasul & 84 & 9 & 208367 & 0.4421 & 0.4522 & 0.1453 & 1.71 \\
Marala & 87 & 3 & 317834 & 0.3576 & 0.3659 & 0.0299 & 0.77 \\
Khanki & 84 & 6 & 362860 & 0.3515 & 0.3618 & 0.0297 & 0.43 \\
Qadirabad & 43 & 2 & 373398 & 0.3764 & 0.2526 & 0.0028 & 1.56 \\
Balloki & 85 & 8 & 92263 & 0.3333 & 0.3968 & 0.0910 & 1.10 \\
Sidhnai & 83 & 7 & 73269 & 0.3700 & 0.4001 & 0.1128 & 0.36 \\
Kotri & 43 & 5 & 382260 & 0.4048 & 0.4094 & 0.2231 & 1.54 \\
Guddu & 29 & 1 & 542290 & 0.3272 & 0.2522 & 0.0246 & 0.85 \\
Sukkur & 30 & 0 & 491594 & 0.3389 & 0.2596 & 0.0109 & 0.67 \\
\hline
\end{tabular}

Table 6. Heterogeneity measure for censored and uncensored samples.

\begin{tabular}{c|c}
\hline Heterogeneity measure & H \\
\hline Uncensored samples & 0.98 \\
Censored samples & 0.72 \\
\hline
\end{tabular}

As $H$ is based on the coefficient of variation and explicates more variation as compared to the coefficient of skewness and coefficient of Kurtosis. For uncensored sample using LM the value of $H=0.98$ and for the censored sample using PLM the value of $H=0.72$. Both measures present similar results but heterogeneity measure based on PLM is smaller showing some edge over LM method. It also implies that after discarding some observation from some sites, the heterogeneity measure of the region is likely to decrease. Hosking and Wallis (2005) preferred to use three parameters distributions like generalize Pareto (GPA), generalize logistic (GLO), generalize extreme value (GEV), generalize normal (GNO) and generalize Pearson 3 type (PE-III) based on L-moments. For PLM only GEV, GLO, and GPA are the distributions whose partial L moments are available (Zakaria and Shabri, 2013). The selection of the distribution is made by Z- statistic. According to the criterion, if the absolute value of $\mathrm{Z}$ statistic is less than 1.64, the distribution will be declared as best one. But in case of more than one distribution satisfying this criterion, the closer the absolute value of Zstatistic to zero, better will be the distribution. The simulation procedure for the calculation of Z-statistic is explained in the previous section.

GNO, GPA, PE-III show that the Z-statistic for these distributions is less than the critical value. But the value of this statistic for $\mathrm{GNO}=0.71$ meets the criterion of the most appropriate distribution for uncensored samples while for GPA $=-0.53$ for censored samples. Results are presented in Table 7. The second best fit distributions using LM and PLM are GPA and GEV respectively.

PLMRD is comparable to LMRD. LMRD and PLMRD are delineated for the described region. Sample regional coefficients of L-skewness/PL-skewness and Lkurtosis/PL-kurtosis are used for LMRD/PLMRD. The ratio of regional sample coefficients of skewness and kurtosis based on LM fall contiguous to the GNO (Fig. 2a) 
while using PLM the ratio falls near to GPA (see Fig. 2b). The results found with Zstatistic and ratio diagrams are similar.

Table 7. Z-Statistic for best fit distribution for censored and uncensored samples

\begin{tabular}{c|c|c|c|c|c}
\hline \multicolumn{7}{c}{ Z-Statistic Value } \\
\hline Method & GNO & PE-III & GEV & GLO & GPA \\
\hline Uncensored sample & 0.71 & -1.76 & 2.14 & 3.04 & -0.83 \\
\hline Censored sample & ---- & ---- & 2.29 & 3.15 & -0.53 \\
\hline
\end{tabular}
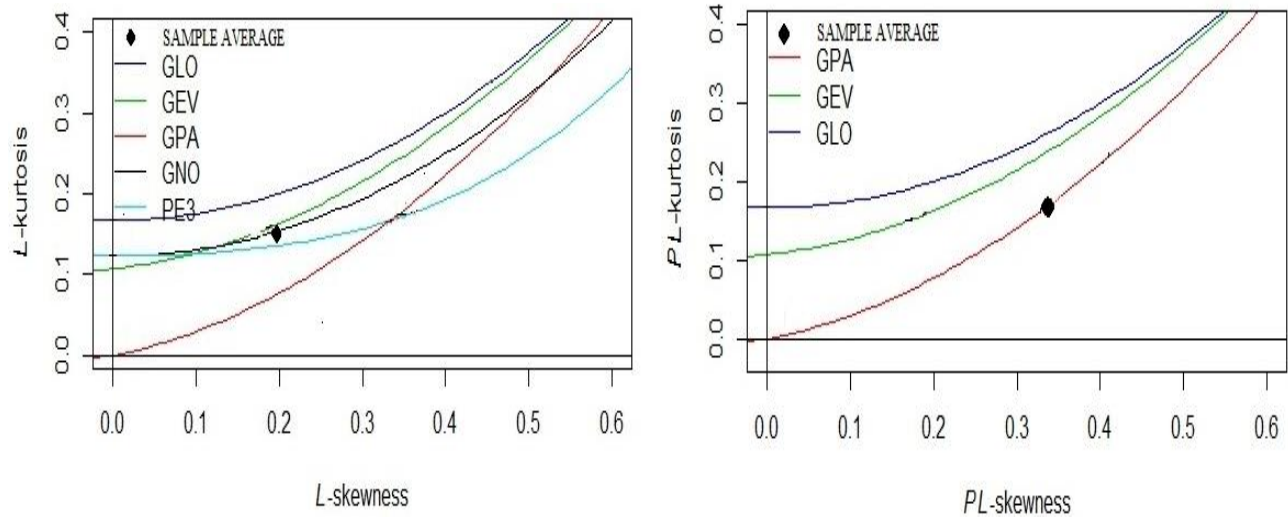

Figure 2. a L-moments ratio diagram for uncensored data; $\boldsymbol{b}$ partial L-moments ratio diagram for censored samples

The regional design flood estimates for the prescribed region corresponding to 2, 5, 10, 20, 50, 100 and 500 return periods (average recurrence period of flood events) using LM and PLM are illustrated in Table 8.

Table 8. Quantile estimation for homogenous region for censored and uncensored samples

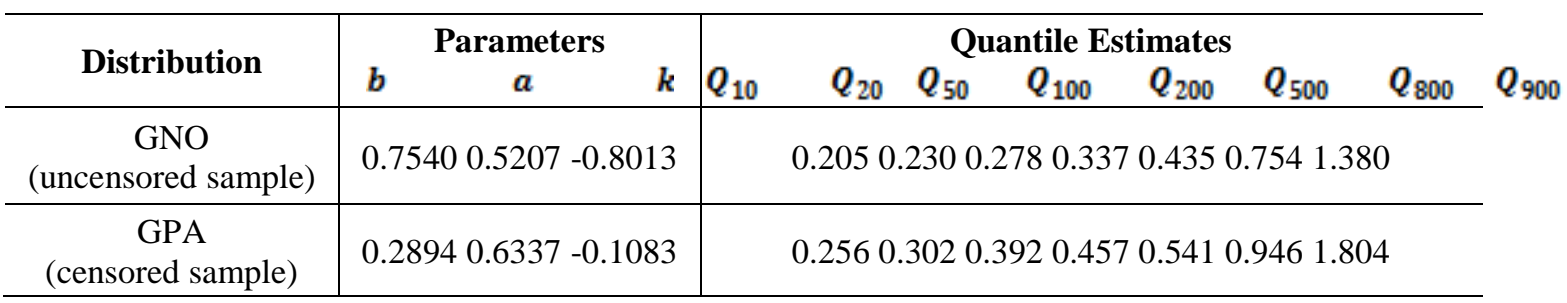

The Monte Carlo simulation procedure based on Regional L-moment algorithm (Hosking and Wallis, 2005) determines the accuracy of estimated quantiles/ growth curves. The repetitions in this process must be larger enough so that the RMSE and bias values are contiguous to the actual RMSE and bias. Therefore, 10000 repetitions are performed (see Table 9). Using PLM, Regional Average Relative RMSE and Bias values, i.e. $R^{R}(F)$ and $B^{R}(F)$ delivered by GPA under PLM are smaller than GNO under LM for all return periods. But the difference is more pronounced at larger return period events for example 100 years and 500 years. 
The at most decrease in $R^{R}$ using PLM as compared to LM up to 20 years return period is $0.9 \%$. Similarly, at most decrease in $R^{R}$ using PLM as compared to LM up to 500 years return period is $4.6 \%$. The at most decrease in $B^{R}$ using LM as compared to LM up to 20 years return period is $0.12 \%$. Similarly, at most decrease in $B^{R}$ using PLM as compared to LM upto 500 years return period is $0.22 \%$. This decrease is more rapid and pronounced at higher return periods. It shows that PLM comparatively outperforms than LM especially at larger events. PLM is useful when our concern is higher return period's events and our target is long-term planning in water resources management. Unnecessary bias and errors due to smaller values of flows could be avoided using PLM. As the main objective of the RFFA is to estimate the quantiles for upper tail of the distribution and get knowledge about the larger return periods, PLM would be a more reasonable and effective choice for such type of design flood estimation. This study reinforces the use of PLM using censored samples. Our results support the outcomes of earlier studies (e.g., Bhattarai, 2004; Zakaria et al., 2011, 2012; Zakaria and Shabri, 2013; Khan et al., 2017) where PLM technique using censored samples outperformed than LM for large return periods estimations.

Table 9. Accuracy assessment for different returns periods using selected distributions

\begin{tabular}{|c|c|c|c|c|c|c|c|c|c|c|}
\hline \multirow{2}{*}{ Method } & \multirow{2}{*}{ Dist. } & \multirow{2}{*}{$\mathbf{F}$} & 0.100 & 0.500 & 0.800 & 0.900 & 0.950 & 0.980 & 0.990 & 0.998 \\
\hline & & & 1 & 2 & 5 & 10 & 20 & 50 & 100 & 500 \\
\hline \multirow{2}{*}{$\begin{array}{c}\text { Uncensored } \\
\text { sample }\end{array}$} & \multirow{2}{*}{ GNO } & $\mathrm{R}_{(\mathrm{F})}^{\mathrm{K}}$ & 0.2470 & 0.0552 & 0.0319 & 0.0560 & 0.0760 & 0.1070 & 0.1330 & 0.2030 \\
\hline & & $\mathrm{B}^{\mathrm{R}}(\mathrm{F})$ & 0.0455 & 0.0054 & 0.0017 & 0.0044 & 0.0016 & 0.0015 & 0.0047 & 0.0043 \\
\hline \multirow{2}{*}{$\begin{array}{l}\text { Censored } \\
\text { sample }\end{array}$} & \multirow{2}{*}{ GPA } & $\mathrm{R}^{\mathrm{R}}(\mathrm{F})$ & 0.2465 & 0.0551 & 0.0309 & 0.0540 & 0.0670 & 0.0890 & 0.1080 & 0.1570 \\
\hline & & $\mathrm{B}^{\mathrm{R}}{ }_{(\mathrm{F})}$ & 0.0449 & 0.0053 & 0.0015 & 0.0032 & 0.0010 & 0.0011 & 0.0032 & 0.0021 \\
\hline
\end{tabular}

\section{Conclusions and recommendations}

PLM and LM estimation methods were applied to annual peak flows data of ten stations located at Indus Basin, Pakistan. No station was appeared to be discordant. On the basis of geographical closeness, stream hydrology and basin morphology one homogenous region is formed and verified through the heterogeneity measure. Zstatistics and ratio diagrams depicted the best fit distributions for both methods. Using LM, GNO was more appropriate choice for the homogenous region while GPA under PLM. The accuracy of the estimated design flood estimates (regional quantiles/growth curves estimates) was assessed through, regional average RRMSE and bias, i.e. $R^{R}(F)$ and $B^{R}(F)$. The decrease in these measures was relatively more at higher return periods under PLM method. Our results support the outcomes of earlier studies (e.g., Bhattarai, 2004; Zakaria et al., 2011, 2012; Zakaria and Shabri, 2013; Khan et al., 2017), where PLM technique using censored samples outperformed than LM for large return periods estimations. During flood frequency analysis, in comparison with LM, PLM describe the data samples in a better way and improve the accuracy of design flood estimates. With the help of PLM, we can mitigate the undesirable influences of small events which they leave on large return period events. Therefore, it is a reasonable and effective method for flood frequency analysis. These estimates would be of great help for designing, planning, and management of different hydrological structures in the 
form of water reservoirs, spillways, headworks, dams, culverts, bridges and other water related structures.

The present study can be extended to other sites of the Indus basin Pakistan, which will help the researchers to make policy implications related to water resources management for the whole country.

Acknowledgements. Authors extend their gratitude to the deanship of scientific research at King Khalid University, Saudi Arabia for providing financial support through research groups program under grant No RGP-1/50/39.

Conflict of interests. Authors have no conflict of interests in publication of this manuscript.

\section{REFERENCES}

[1] Abida, H., Ellouze, M. (2007): Probability distribution of flood flows in Tunisia. Hydrology and Earth System Sciences Discussions 4(2): 957-981.

[2] Afreen, S., Muhammad, F. (2012): Flood frequency analysis of various dams and barrages in Pakistan. - Irrigation and Drainage 61(1): 116-128.

[3] Ahmad, I., Shah, S. F., Mahmood, I., Ahmad, Z. (2013): Modeling of monsoon rainfall in Pakistan based on Kappa distribution. - Science International (Lahore) 25(2): 333-336.

[4] Ahmad, I., Fawad, M., Mahmood, I. (2015): At-site flood frequency analysis of annual peak stream flows in Pakistan using robust estimation methods. - Polish Journal of Environmental Studies 24(6).

[5] Ahmad, I., Fawad, M., Abbas, A., Saghir, A. (2016a): Probability modeling of low flows at different sites of Indus basin in Pakistan using L-moments and TL-moments. Pakistan Journal of Science 68(1): 86-93.

[6] Ahmad, I., Fawad, M., Akbar, M., Abbas, A., Zafar, H. (2016b): Regional frequency analysis of annual peak flows in Pakistan using linear combination of order statistics. Polish Journal of Environmental Studies 25(6): 1-10.

[7] Ahmad, I., Yasin, M., Fawad, M., Saghir, A. (2017): Regional frequency analysis of Low flows using L. moments for Indus Basin, in Pakistan. - Pakistan Journal of Science 69(1): 75-83.

[8] Ali, A. (2013): Indus Basin Floods: Mechanisms, Impacts, And Management. - Asian Development Bank Bulletin. ADP, Manila.

[9] Asikoglu, O. L. (2018): parent flood frequency distribution of Turkish rivers. - Polish Journal of Environmental Studies 27(2): 1-7.

[10] Bhattarai, K. P. (2004): Partial L-moments for the analysis of censored flood samples/Utilisation des L-moments partiels pour l'analyse d'échantillons tronqués de crues. - Hydrological Sciences Journal 49(5): 855-868.

[11] Bora, D. J., Borah, M. (2017): Regional analysis of maximum rainfall using L-moment and TL-moment: a comparative case study for the north East India. - Journal of Applied and Natural Science 9(4): 2366-2371.

[12] Caporali, E., Chiarello, V., Petrucci, A. (2018): Regional frequency analysis and geoadditive modeling for design storm estimates in the Arno river basin (Italy). Environmental and Ecological Statistics 25(1): 31-52.

[13] Du, H., Xia, J., Zeng, S. (2014): Regional frequency analysis of extreme precipitation and its spatio-temporal characteristics in the Huai River Basin, China. - Natural Hazards 70(1): 195-215.

[14] Eslamian, S. (ed.) (2014): Handbook of Engineering Hydrology: Modeling, Climate Change, and Variability. - CRC Press, Boca Raton, FL. 
[15] Fowler, H. J., Kilsby, C. G. (2003): A regional frequency analysis of United Kingdom extreme rainfall from 1961 to 2000. - International Journal of Climatology 23(11): 13131334.

[16] Glaves, R., Waylen, P. R. (1997): Regional flood frequency analysis in Southern Ontario using L-moments. - Canadian Geographer/Le Géographe Canadien 41(2): 178-193.

[17] Greenwood, J. A., Landwehr, J. M., Matalas, N. C., Wallis, J. R. (1979): Probability weighted moments: definition and relation to parameters of several distributions expressable in inverse form. - Water Resources Research 15(5): 1049-1054.

[18] Hosking, J. R. (1990): L-moments: analysis and estimation of distributions using linear combinations of order statistics. - Journal of the Royal Statistical Society. Series B (Methodological) 55(1): 105-124.

[19] Hosking, J. R. M., Wallis, J. R. (2005): Regional Frequency Analysis: An Approach Based on L-Moments. - Cambridge University Press, Cambridge, UK.

[20] Hussain, Z. (2011): Application of the regional flood frequency analysis to the upper and lower basins of the Indus River, Pakistan. - Water Resources Management 25(11): 2797 2822.

[21] Kar, K. K., Yang, S. K., Lee, J. H., Khadim, F. K. (2017): Regional frequency analysis for consecutive hour rainfall using L-moments approach in Jeju Island, Korea. Geoenvironmental Disasters 4(1): 18-24.

[22] Khan, S. A., Hussain, I., Hussain, T., Faisal, M., Muhammad, Y. S., Mohamd Shoukry, A. (2017): Regional frequency analysis of extremes precipitation using L-moments and partial L-moments. - Advances in Meteorology 2017(1): 1-20.

[23] Khanmohammadi, N., Rezaie, H., Montaseri, M., Behmanesh, J. (2018): Regional probability distribution of the annual reference evapotranspiration and its effective parameters in Iran. - Theoretical and Applied Climatology 134(1-2): 411-422.

[24] Kjeldsen, T. R., Smithers, J. C., Schulze, R. E. (2002): Regional flood frequency analysis in the KwaZulu-Natal province, South Africa, using the index-flood method. - Journal of Hydrology 255(1-4): 194-211.

[25] Kochanek, K., Strupczewski, W. G., Singh, V. P., Weglarczyk, S. (2008): The PWM large quantile estimates of heavy tailed distributions from samples deprived of their largest element. - Hydrological Sciences Journal 53(2): 367-386.

[26] Mohd Baki, A., Yusof, M., Asmani, D., Atan, I., Halim, M., Farina, N. (2015): Regional flow frequency analysis on Peninsular Malaysia using L-moments. - Jurnal Intelek 9(1): 63-68.

[27] Moisello, U. (2007): On the use of partial probability weighted moments in the analysis of hydrological extremes. - Hydrological Processes: An International Journal 21(10): 1265-1279.

[28] Naghettini, M. (2017): Fundamentals of Statistical Hydrology. - Springer, Cham.

[29] Ngongondo, C. S., Xu, C. Y., Tallaksen, L. M., Alemaw, B., Chirwa, T. (2011): Regional frequency analysis of rainfall extremes in Southern Malawi using the index rainfall and L-moments approaches. - Stochastic Environmental Research and Risk Assessment 25(7): 939-955.

[30] Noto, L. V., La Loggia, G. (2009): Use of L-moments approach for regional flood frequency analysis in Sicily, Italy. - Water resources management 23(11): 2207-2229.

[31] Rahman, A. S., Rahman, A., Zaman, M. A., Haddad, K., Ahsan, A., Imteaz, M. (2013): A study on selection of probability distributions for at-site flood frequency analysis in Australia. - Natural Hazards 69(3): 1803-1813.

[32] Rasul, G., Mahmood, A., Sadiq, A., Khan, S. I. (2012): Vulnerability of the Indus delta to climate change in Pakistan. - Pakistan Journal of Meteorology 8(16): 89-107.

[33] Saf, B. (2009): Regional flood frequency analysis using L-moments for the West Mediterranean region of Turkey. - Water Resources Management 23(3): 531-551.

[34] Saf, B. (2010): Assessment of the effects of discordant sites on regional flood frequency analysis. - Journal of Hydrology 380(3-4): 362-375. 
[35] Seckin, N., Haktanir, T., Yurtal, R. (2011): Flood frequency analysis of Turkey using L-moments method. - Hydrological Processes 25(22): 3499-3505.

[36] Sung, J. H., Kim, Y. O., Jeon, J. J. (2018): Application of distribution-free nonstationary regional frequency analysis based on L-moments. - Theoretical and Applied Climatology 133(3-4): 1219-1233.

[37] Wang, Q. J. (1990): Estimation of the GEV distribution from censored samples by method of partial probability weighted moments. - Journal of Hydrology 120(1-4): 103114.

[38] Wang, Q. J. (1996): Using partial probability weighted moments to fit the extreme value distributions to censored samples. - Water Resources Research 32(6): 1767-1771.

[39] Yang, T., Shao, Q., Hao, Z. C., Chen, X., Zhang, Z., Xu, C. Y., Sun, L. (2010): Regional frequency analysis and spatio-temporal pattern characterization of rainfall extremes in the Pearl River Basin, China. - Journal of Hydrology 380(3-4): 386-405.

[40] Yang, T., Xu, C. Y., Shao, Q. X., Chen, X. (2010): Regional flood frequency and spatial patterns analysis in the Pearl River Delta region using L-moments approach. - Stochastic Environmental Research and Risk Assessment 24(2): 165-182.

[41] Yue, S., Wang, C. (2004): Determination of regional probability distributions of Canadian flood flows using L-moments. - Journal of Hydrology (New Zealand) 43(1): 59-73.

[42] Zakaria, Z. A., Shabri, A. (2013): Regional frequency analysis of extreme rainfalls using partial L moments method. - Theoretical and Applied Climatology 113(1-2): 83-94.

[43] Zakaria, Z. A., Shabri, A., Ahmad, U. N. (2011): Estimation of generalized Pareto distribution from censored flood samples using partial L-moments. - Journal of Mathematics Research 3(1): 112-118.

[44] Zakaria, Z. A., Shabri, A., Ahmad, U. N. (2012): Regional frequency analysis of extreme rainfalls in the West Coast of Peninsular Malaysia using partial L-Moments. - Water Resources Management 26(15): 4417-4433.

[45] Zakaria, Z. A., Shabri, A., Awang, M. K. (2017): Regional frequency analysis of streamflow based on partial L-moments approach. - Far East Journal of Mathematical Sciences 101(4): 689-695.

[46] Zaman, M. A., Rahman, A., Haddad, K. (2012): Regional flood frequency analysis in arid regions: A case study for Australia. - Journal of Hydrology 475(19): 74-83.

[47] Zhang, Q., Qi, T., Singh, V. P., Chen, Y. D., Xiao, M. (2015): Regional frequency analysis of droughts in China: a multivariate perspective. - Water Resources Management 29(6): 1767-1787.

[48] Zin, W. Z. W., Jemain, A. A., Ibrahim, K. (2009): The best fitting distribution of annual peak rainfall in Peninsular Malaysia based on methods of L-moment and LQ-moment. Theoretical and Applied Climatology 96(3-4): 337-344. 